\title{
Robust Controller for a Vision Feedback Based Telepointer
}

\author{
Shah Newaz Mohammad Abdul Kader, Mohd. Marzuki Mustafa, Aini Hussain \\ Department of Electrical, Electronics and Systems Engineering, Faculty of Engineering and Built Environment, \\ Universiti Kebangsaan Malaysia, Malaysia
}

\begin{tabular}{l}
\hline \hline Article Info \\
\hline Article history: \\
Received Jun 30, 2016 \\
Revised Sep 08, 2016 \\
Accepted Sep 22, 2016 \\
\hline
\end{tabular}

\section{Keyword:}

Discrete PID controller

Laser pointer

Teleconsultation

Telepointer

Vision feedback

\begin{abstract}
Telepointer is a very useful tool for teleconsultation and teleproctoring, whereby a telepointer via teleconferencing is a perfect example of computersupported cooperative work (CSCW) and digital telepresence. To this end, many telepointers are introduced for digital telepresence. However, there are still concerns regarding the speed of response and robustness of the system. It is rather difficult to model the actual system in order to design the controller. This paper described the development of a telepointer and its controller for a real time communication using vision feedback. The main focus of this study was to control the Laser Pointer (LP) with a discrete time PID (proportional-integral-derivative) controller which was tuned using Ziegler-Nichols $(\mathrm{ZN})$ method. The results indicated that the tuned controller bring about fast response with no overshoot and steady state errors at the output response. The controller was shown to be robust against changes in sampling time and external disturbance.
\end{abstract}

Copyright $\odot 2016$ Institute of Advanced Engineering and Science. All rights reserved.

\section{Corresponding Author:}

Shah Newaz Mohammad Abdul Kader,

Department of Electrical, Electronics and Systems Engineering,

Faculty of Engineering and Built Environment,

Universiti Kebangsaan,

43600 Bangi, Selangor, Malaysia.

Email: eee.joy06@yahoo.com

\section{INTRODUCTION}

Teleproctoring is mentoring and evaluating of clients from distance with the involvement of broadband connectivity, power cams, and sophisticated videoconferencing equipments. It is a real time interactive instruction of techniques by an expert, who is in one location and the client is in another remote location. With the aid of telepointer a clinicians can point accurately to different areas of the patients in remote location through long distance communication such as internet. A basic telepointer system has a video display as user interface, a pointing device, a Personal Computer (PC) and a web camera. The camera takes the images at the local end and transmitted to the remote end. The local end has a pointing device (e.g.: cursor mouse) to point to a specific object on the user display screen which is synchronized between the both ends [1]. In recent years, several trials were done to improve the telepresence of the subspecialists by integrating a remote control telepointer. In 1998, S. Mann [2] introduced the first telepointer, which was a wearable, hands free telepointer which can point different objects in a remote location. This telepointer has been experimentally used in grocery shop to indicate particular product from remote location. It was also used as a teaching tool in the university.

Many other experiments were done with different mechanisms to use a remotely controlled LP as a telepointer. Most of them focused on the practical potential applications but does not explain much about the performance and robustness of the control system that remotely controlled the telepointer. The aim of this paper is to describe the development of a vision feedback based telepointer with the focus on the control system of this telepointer. Properly tuned controller is an important aspect of this servo mounted LP to avoid sluggish output response, overshoot, steady state error and operational sensitivities such as external 
disturbances [1]. In our system, the controller will be based on the widely used industrial PID controller scheme as the working principle is intuitively well understood. The proportional term controls the speed of response in the sense of bringing the output closer to the set point and able to reduce the effect of small disturbances. The integral term will ensure that controlled system is robust against constant disturbance. Adding the derivative term further improves the control as it tends to moderate the effect of the P and I terms due to its ability to predict ahead [3]. Ziegler-Nichols based PID controller is used precisely in a teleoperation scheme [4]. However, to ensure good system response, the parameters that determine the strength of these 3 control actions need to be properly tuned. Because of the difficulty in deriving a mathematical model of a vision feedback based telepointer system, tuning methods based on the process model of the system cannot be used. While a "trial and error" method can be used to obtain the controller parameters, the tuning process can take a long time. For this reason, we have adopted a more systematic although empirical, tuning the PID controller parameters using closed loop Ziegler-Nichols method.

\section{VISION FEEDBACK BASED TELEPOINTER SYSTEM}

Figure 1 shows overall teleconsultation system with remotely controlled LP, which is used as a telepointer.This system mainly consist two PCs located in two different locations. The client PC is at the base station and the server PC is at the work station. Both PCs are equipped with normal web camera and audio visual system. The client PC and the server PC are connected via Internet/LAN(Local Area Network) to establish a real time audio, video, and data streaming. The servo mounted LP is interfaced with the server PC through a USB port. This hardware system consists of a DAC (Digital to Analog Converter) and a telepointer. At the work station the patient is positioned in the field of view of the web cam and within the range of the LP. A general physician is normally present to operate the treatment at the work station. At the remote base station location, a subspecialist physician is present to communicate with the general physician concerning the operative technique via the video conference link and telepointer. In this overall system at the base station, the remote subspecialist physician is called the proctoring physician and at the work station the general physician is called the proctored physician. At the work station the patient is positioned in the field of view of the web cam and within the range of the LP .

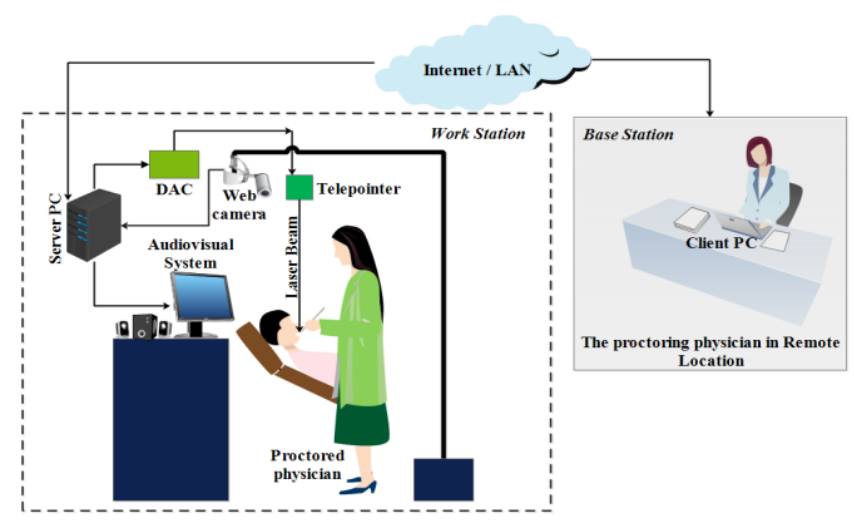

Figure 1. Overall Teleconsultation System with Remotely Controlled LP

Vision feedback is a feedback based on information derived from two-dimensional images such as taken using camera. The information derived from these images requires the use of image processing or computer vision techniques [5]. The goal of all vision feedback control systems is to minimalize an error, which is usually defined by

$$
e(t)=s(m(t), a)-s^{*}
$$

where, s $(\mathrm{m}(\mathrm{t}), \mathrm{a})$ is image features, $\mathrm{m}(\mathrm{t})$ is image coordinates of interest points, a is camera intrinsic parameters and $\mathrm{s}^{*}$ is the desired value of the image features [6]. Figure 2 shows a general block diagram of Vision Feedback system for a telepointer.

Figure 3 depicts the vision feedback control system for telepointer system can be elaborately. The use of vision feedback made the system more robust against disturbance and does not require precise 
calibration and elaborate set-up. the target position of the $\mathrm{LP} \mathrm{s}^{*}=\left(\mathrm{X}_{\mathrm{t}}, \mathrm{Y}_{\mathrm{t}}\right)$ is given by the mouse cursor of the client PC that display the real time video image of the patient captured by web camera at the work station.

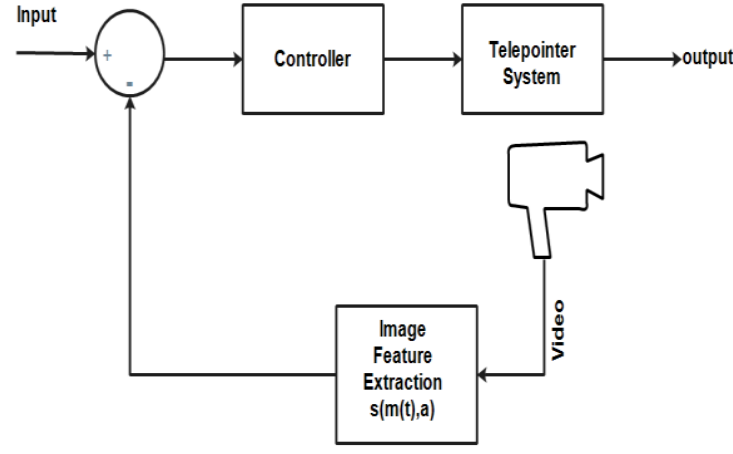

Figure 2. Vision Feedback System for Telepointer

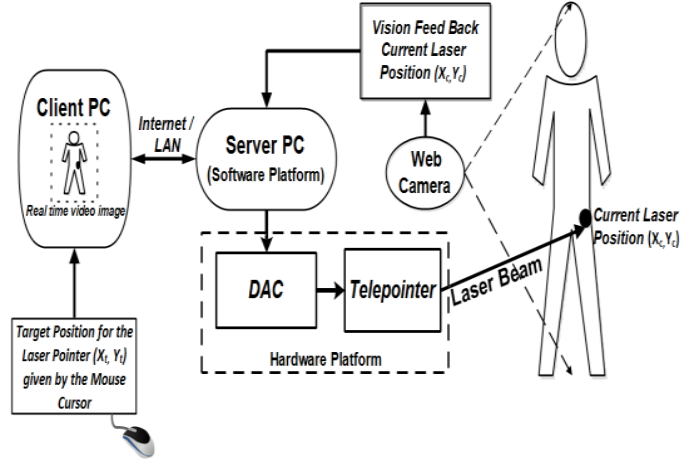

Figure 3. Vision Feedback Based Telepointer System Outline

This target coordinate information $\left(\mathrm{X}_{\mathrm{t}}, \mathrm{Y}_{\mathrm{t}}\right)$ is transferred to the server PC via internet. At the server $\mathrm{PC}$, from the same real time the video image, the current position of LP $s=\left(X_{c}, Y_{c}\right)$ is detected and tracked by a laser detection and tracking algorithm in the server PC. This current coordinate information of LP is then used as feedback to the PID controller in server PC. The output of the controller is send to the control box that converts these digital signals to analog DC voltage signals which control servo motors that moved the LP.

\subsection{Hardware Platform}

Figure 4 summarizes the functionality of whole hardware platform. The DAC is connected to the server PC via USB Port. The DAC output channels are connected to the driver cards of Galvanometer Optical scanner. Galvanometer Optical scanner has two servo mounted mirrors to reflect the laser beam along the $\mathrm{x}$ axis and y-axis. These servo motors and the driver cards have built-in feedback where the motors will rotate to angles proportional to the input voltages. Ideally the input voltages to the driver cards can be calibrated to move the laser spot to specified location, but this open loop control will be sensitive to distant between the laser source and the object, and the mounting orientation of the LP. For this reason an external control loop is required that utilised the laser spot location as feedback signal. Laser beam is fixed perpendicularly with the mirrors of that scanner and focused at the center of mirrors. The laser spot from the reflected beam can be controlled by rotating the mirrors at certain angle.

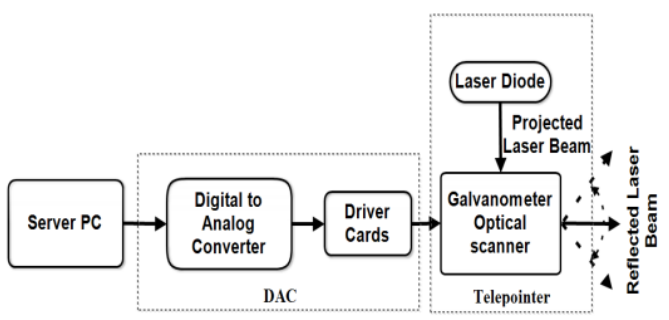

Figure 4. Hardware Platform

\subsection{Software Platform}

In The server PC, software platform consist of integrated three modules developed using C\#. A real time AVD (Audio, Video, Data) streaming module setup a network though Internet/LAN between the server PC and client PC. The LP detection and tracking module is a webcam based LP detection and tracking application. In this module, Andrew Kirillov's motion detection code is used and the AForge.NET framework 
is used for image processing. The laser point detection algorithm is based on finding the brightest pixel in the webcam's field. This simple algorithm is chosen to enable detection to be done quickly without incurring significant processing time, hence delay in the feedback. To further increase the image processing speed, UnsafeBitmap class was used to access any pixel data in a short time [7]. The third module is the control module where control signal is computed using discrete time PID controller. The implementation of the discrete time PID controller used in this module is described using the pseudocode [8] below:

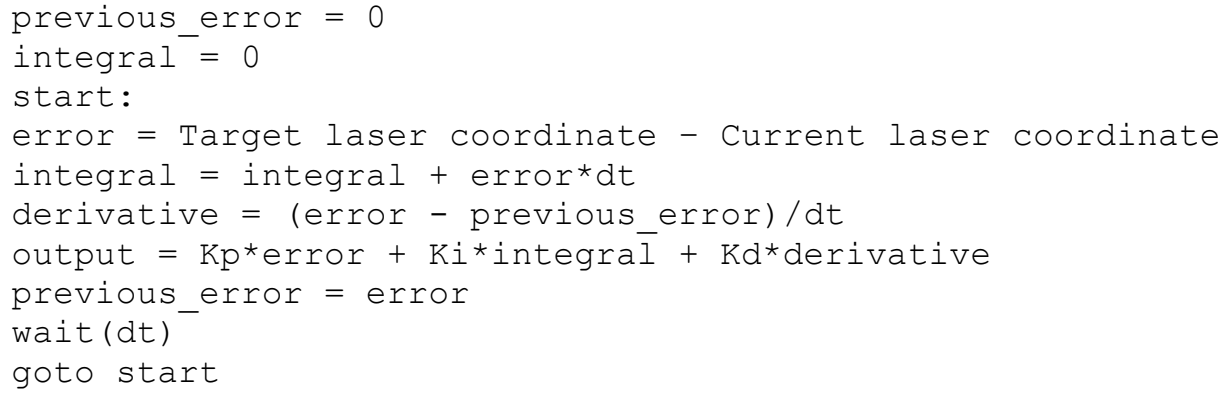

where, $\mathrm{dt}$ is sampling time.

\subsection{PID Controller Design}

Figure 5 shows the block diagram of the control system. Here, $\mathrm{C}(\mathrm{z})$ is the controller and $\mathrm{P}(\mathrm{z})$ is telepointer system. The actual system has two separate PID controllers each for $x$-axis and y-axis. The general form of the continuous time PID algorithm is,

$$
u(t)=k_{p} \cdot e(t)+k_{i} \cdot \int_{0}^{t_{n}} e(\tau) d \tau+k_{d} \frac{d}{d t} e(t)
$$

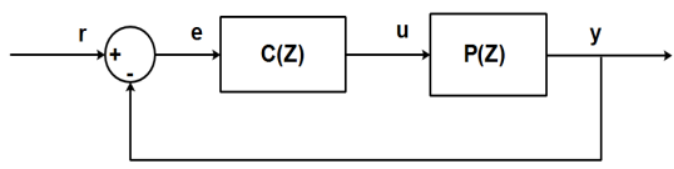

Figure 5. Control System

where $\mathrm{e}(\mathrm{t})=\mathrm{r}(\mathrm{t})-\mathrm{y}(\mathrm{t}), \mathrm{y}$ is output value (Current laser coordinate $\mathrm{X}_{\mathrm{c}}, \mathrm{Yc}$ ), $\mathrm{r}$ is input value (Target laser coordinate $\left.\mathrm{X}_{\mathrm{t}}, \mathrm{Y}_{\mathrm{t}}\right), k_{p}$ is Proportional gain; $\mathrm{k}_{\mathrm{i}}$ is Integral gain, $\mathrm{k}_{\mathrm{d}}$ is Derivative gain, $\mathrm{t}_{\mathrm{n}}$ is Time, $\tau$ is Variable of integration which takes values from time 0 to the present $t_{n}$. With a sampling time $\delta$ t, the discretized form of the PID algorithm is,

$$
\mathrm{u}\left(\mathrm{t}_{\mathrm{n}}\right)=\mathrm{k}_{\mathrm{p}} \cdot \mathrm{e}\left(\mathrm{t}_{\mathrm{n}}\right)+\mathrm{k}_{\mathrm{i}} \sum_{\mathrm{i}=1}^{\mathrm{n}} \mathrm{e}\left(\mathrm{t}_{\mathrm{i}}\right) \delta \mathrm{t}+\mathrm{k}_{\mathrm{d}} \frac{\mathrm{e}\left(\mathrm{t}_{\mathrm{n}}\right)-\mathrm{e}\left(\mathrm{t}_{\mathrm{n}-1}\right)}{\delta \mathrm{t}}
$$

Let $\mathrm{T}_{\mathrm{s}}$ be the sampling time. The discrete time $\mathrm{Z}$ transfer function of the PID controller is

$$
\mathrm{C}(\mathrm{z})=\mathrm{k}_{\mathrm{p}}+\mathrm{k}_{\mathrm{i}} \frac{\mathrm{T}_{\mathrm{s}} \cdot \mathrm{z}}{\mathrm{z}-1}+\mathrm{k}_{\mathrm{d}} \frac{\mathrm{z}-1}{\mathrm{~T}_{\mathrm{s}} \cdot \mathrm{z}}
$$

There are several methods that can be used to determine the above controller parameters $k_{p}, k_{i}$ and $k_{d}$ [9]. If the transfer function of the plant is known, there are many available design techniques can be used either based on classical control, optimal control or artificial intelligence such as fuzzy logic. If the plant model $\mathrm{P}(\mathrm{z})$ is unknown then those controllers can be tuned manually by trial and error, or using the open loop or closed loop Ziegler-Nichols tuning method. The closed loop method is used here because the tuning method will automatically and intrinsically incorporate all the dynamics associated with the discrete time implementation. Since this tuning method originated from heuristic principle, it does not always give the best performance in all cases, but can serve as useful starting point for further tuning. The first step is to test whether the proportional control gain is positive or negative. Then, $\mathrm{k}_{\mathrm{i}}$ and $\mathrm{k}_{\mathrm{d}}$ are set to zero and $\mathrm{k}_{\mathrm{p}}$ value is 
increased until it generates a periodic oscillation at the output response. This critical $k_{p}$ value is the 'ultimate gain' $k_{u}$. The period where the oscillation occurs is called $T_{u}$ 'ultimate period'. Based on the value of these two parameters, the PID controller parameters $k_{p}, k_{i}, k_{d}$ are calculated according to the Table 1 [10]. For the designed controller $\mathrm{C}(\mathrm{z})$, three desired performance criteria are rise time $\leq 0.05 \mathrm{~s}$, settling time $\leq 0.1 \mathrm{~s}$ and no overshoot.

Table 1. Ziegler-Nichols Method

\begin{tabular}{cccc}
\hline Controller Type & $\mathrm{k}_{\mathrm{p}}$ & $\mathrm{k}_{\mathrm{i}}$ & $\mathrm{k}_{\mathrm{d}}$ \\
\hline $\mathrm{P}$ & $0.5 * \mathrm{k}_{\mathrm{u}}$ & - & - \\
PI & $0.45 * \mathrm{k}_{\mathrm{u}}$ & $1.2 * \mathrm{k}_{\mathrm{p}}$ & - \\
PID & $0.6 * \mathrm{k}_{\mathrm{u}}$ & $2 * \mathrm{k}_{\mathrm{p}} / \mathrm{T}_{\mathrm{u}}$ & $\mathrm{k}_{\mathrm{p}} * \mathrm{~T}_{\mathrm{u}} / 8$ \\
\hline
\end{tabular}

\subsection{PID Controller Tuning}

The servo motors for the $\mathrm{x}$ and $\mathrm{y}$ axes were controlled by two independent PID controllers $\mathrm{C}_{\mathrm{x}}(\mathrm{z})$ and $\mathrm{C}_{\mathrm{y}}(\mathrm{z})$ respectively. Based on the system configuration and image coordinates system, when positive step control signals DC voltages $\mathrm{V}_{\mathrm{x}}$ and $\mathrm{V}_{\mathrm{y}}$ were given as inputs to the system, the laser beam was deflected to negative directions in $\mathrm{x}$ and $\mathrm{y}$ axes. Hence, the DC gain of the system was negative. The sampling time was chosen $\mathrm{Ts}=0.002 \mathrm{~s}$. This was the fastest sampling time that can be used to allow for all the video processing and other processes related to the implementation of the controller and communication to be completed. The tuning process for the controller $\mathrm{C}_{\mathrm{x}}(\mathrm{z})$ was started with all the values of $\mathrm{k}_{\mathrm{i}}$ and $\mathrm{k}_{\mathrm{d}}$ set to zero. The value of $\mathrm{k}_{\mathrm{p}}$ was initially set to -1 and resulted in the output to be unstable. Then the value of $k_{p}$ was gradually decreased until at the value of $\mathrm{k}_{\mathrm{p}}=-0.001$ the system output became stable. The value of $\mathrm{k}_{\mathrm{p}}$ was then gradually increased to -0.003 until it created an oscillation at the output response.

Although the Ziegler-Nichols closed loop tuning method requires the system to have constant amplitude oscillations to determine the ultimate gain and the oscillation period, we have found that it was sufficient to obtain the gain that yield damped oscillation with 5 cycles before the output settled. This method avoided the difficulty in obtaining the critical stability condition and also the potential damage to the equipment. This critical $\mathrm{k}_{\mathrm{p}}$ value was assigned to be 'ultimate gain' $\mathrm{k}_{\mathrm{u}}=-0.003$. From this output response the 'ultimate period' $\mathrm{T}_{\mathrm{u}}$ was measured to be $0.004 \mathrm{~s}$. Similarly, the same process was done for the $\mathrm{y}$-axis controller $\mathrm{C}_{\mathrm{y}}(\mathrm{z})$. For this controller, the value of $\mathrm{k}_{\mathrm{u}}$ was found to be -0.004 and the 'ultimate period' $\mathrm{T}_{\mathrm{u}}$ was measured $0.004 \mathrm{~s}$.

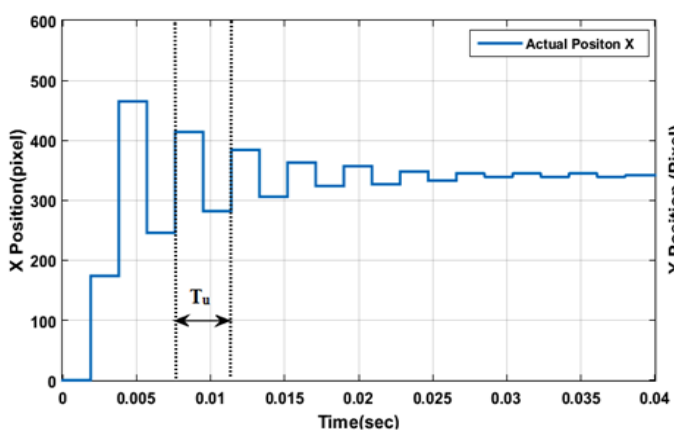

(a)

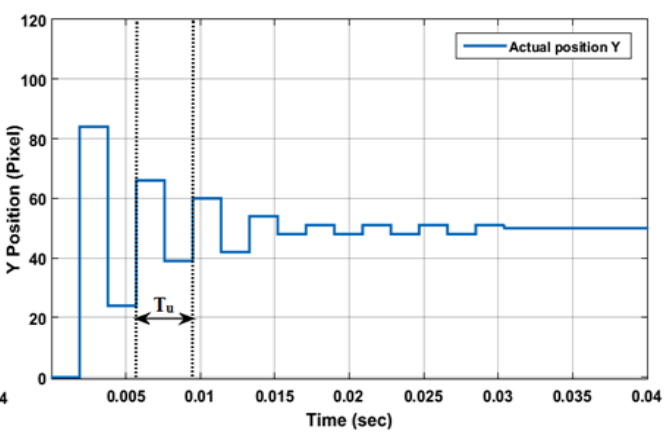

(b)

Figure 6. (a) A damped Oscillation in the $\mathrm{x}$-axis Output when $\mathrm{k}_{\mathrm{p}}=-0.003$, (b) A Damped Oscillation in the $\mathrm{y}$-axis Occurred when $\mathrm{k}_{\mathrm{p}}=-0.004$

Figure 6(a) and Figure 6(b) respectively show the damped oscillations occurred in the $\mathrm{x}$-axis and $\mathrm{y}$-axis outputs, when value of $\mathrm{k}_{\mathrm{p}}$ in $\mathrm{C}_{\mathrm{x}}(\mathrm{z})$ was gradually increased to -0.003 and value of $\mathrm{k}_{\mathrm{p}}$ in $\mathrm{C}_{\mathrm{y}}(\mathrm{z})$ was gradually increased to -0.004 . From these output responses the 'ultimate period' $T_{u}$ was measured to be 0.004 s both for $\mathrm{C}_{\mathrm{x}}(\mathrm{z})$ and $\mathrm{C}_{\mathrm{y}}(\mathrm{z})$. 


\section{RESULTS AND ANALYSIS}

Based on the value of $k_{u}$ and $T_{u}$ the controller parameters $k_{p}, k_{i}, k_{d}$ were calculated according to the tuning rules given in Table 1 . The summary of the controller parameters and their corresponding rise times, setting times and over shoot are given in Table 2.

Table 2. Controller Parameters and Performance

\begin{tabular}{ccccccccc}
\hline Parameters & $\mathrm{k}_{\mathrm{u}}$ & $\mathrm{T}_{\mathrm{u}}$ & $\mathrm{k}_{\mathrm{p}}$ & $\mathrm{k}_{\mathrm{i}}$ & $\mathrm{k}_{\mathrm{d}}$ & Rise time & Settling time & Overshoot \\
\hline Controller Cx $(\mathrm{z})$ & -0.003 & -0.004 & -0.0018 & -0.9 & -0.0000009 & $0.04 \mathrm{sec}$ & $0.074 \mathrm{sec}$ & No o.s \\
Controller Cy $(\mathrm{z})$ & -0.004 & -0.004 & -0.0024 & -1.2 & -0.0000012 & $0.04 \mathrm{sec}$ & $0.072 \mathrm{sec}$ & No o.s \\
\hline
\end{tabular}

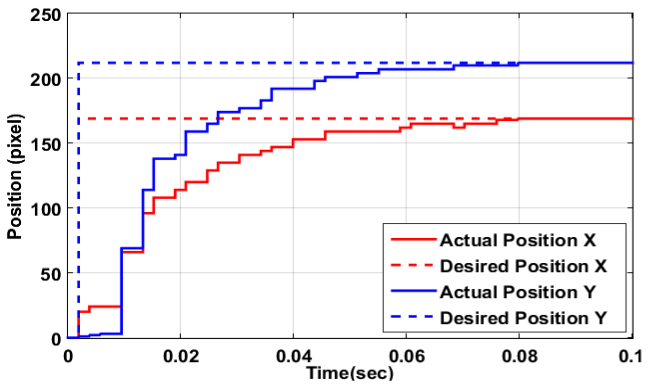

(a)

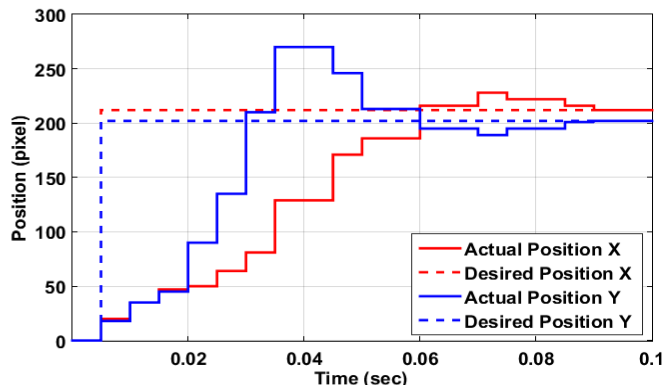

(b)

Figure 7. (a) System Output Response for Controllers Tuned Using Z-N Method (b) System Output Response for the Detuned Controllers

Figure 7(a) show the closed loop responses using these set of $\mathrm{k}_{\mathrm{p}}, \mathrm{k}_{\mathrm{i}}, \mathrm{k}_{\mathrm{d}}$ values for $\mathrm{C}_{\mathrm{x}}(\mathrm{z})$ and $\mathrm{C}_{\mathrm{y}}(\mathrm{z})$ controllers. All three performance criteria (rise time $\leq 0.05 \mathrm{~s}$; settling time $\leq 0.1 \mathrm{~s}$ and no overshoot) were met with the $\mathrm{ZN}$ method. We found that further fine tuning of these controller parameters did not result in better control performance.

Figure 7(b) show the output responses when the controllers are detuned. To get some indication on the tuning method effectiveness, the controller parameters given in Table 2 were detuned by doubling the values of $k_{i}$ and halved the values of $k_{d}$ in the $C_{x}(z)$ and $C_{y}(z)$ controllers. $C_{x}(z)$ gave slower rise time and settling time with $7.5 \%$ overshoot, $\mathrm{C}_{\mathrm{y}}(\mathrm{z})$ gave faster rise time, slower settling time with $33.6 \%$ overshoot. Results show that Z-N method can be effectively used to tune the controller for the tele pointer system.

\subsection{Robustness against Changes in Sampling Time}

The choice of sampling time is crucial in the implementation of discrete time control system. The selection of the sampling time need to take consideration of the closed loop system time constant and also time required to compute the control signal. The main computational load in implementing the controller is the image processing to locate the laser spot. This processing time will be dependent on the speed or computing power of the computer used. Hence, there is a need to study the effect on the performance of the system when different sampling times are used. To study the robustness of the system against different sampling time, delay was purposely introduced in the program code of the controller.
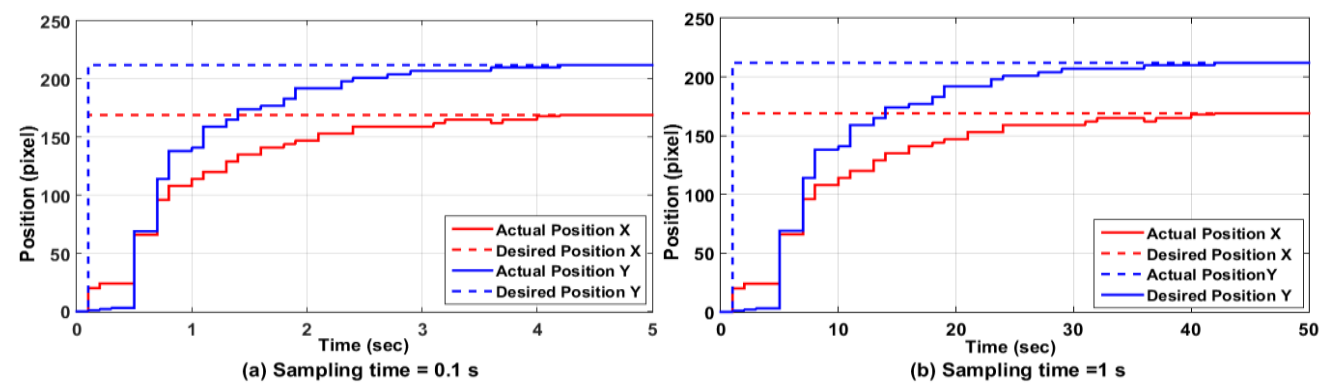

Figure 8. System Output Response with Different Sampling Times (a) $\mathrm{T}_{\mathrm{s}}=0.1 \mathrm{~s}$ and b) $\mathrm{T}_{\mathrm{s}}=1 \mathrm{~s}$ 
Figure 8(a) and 8(b) show the system output responses when the sampling time was increased to $0.1 \mathrm{~s}$ and $1 \mathrm{~s}$. It shows that although the responses were slower as expected because of the delay, there was no overshoot and most importantly is that the closed loop system remained stable. Although the system performance will degrade with longer sampling time, it will not result in complete malfunction of the system. It can be concluded that the controlled system is robust against changes in the sampling time.

\subsection{Robustness against External Disturbance}

For this system, the most likely disturbance will be the LP physical displacement which usually happen as the user repositioned the LP to get the optimum distance and orientation with respect to the patient position.

Figure 9 shows the output when the LP was intentionally displaced. When laser spot was settled at the target positon $(224,214)$ in the $x$ and $y$ direction. The first instance at $0.62 \mathrm{~s}$ the pointer was physically displaced that caused the laser spot to move to $(45,130)$. The control action in the PID controller was able to bring the output to the target location within 0.03s. Similar observations can also be made during the occurrences of disturbances at $1.5 \mathrm{~s}$ and $2.48 \mathrm{~s}$, when the laser spot was physically displaced respectively from its target position to position $(150,63)$ and position $(417,348)$. In all instances, the disturbance were corrected within $0.03 \mathrm{~s}$ which is considered as very fast. In short, the proposed method was able to reposition the LP without the need for elaborate set-up of the instrument and calibration prior to use.
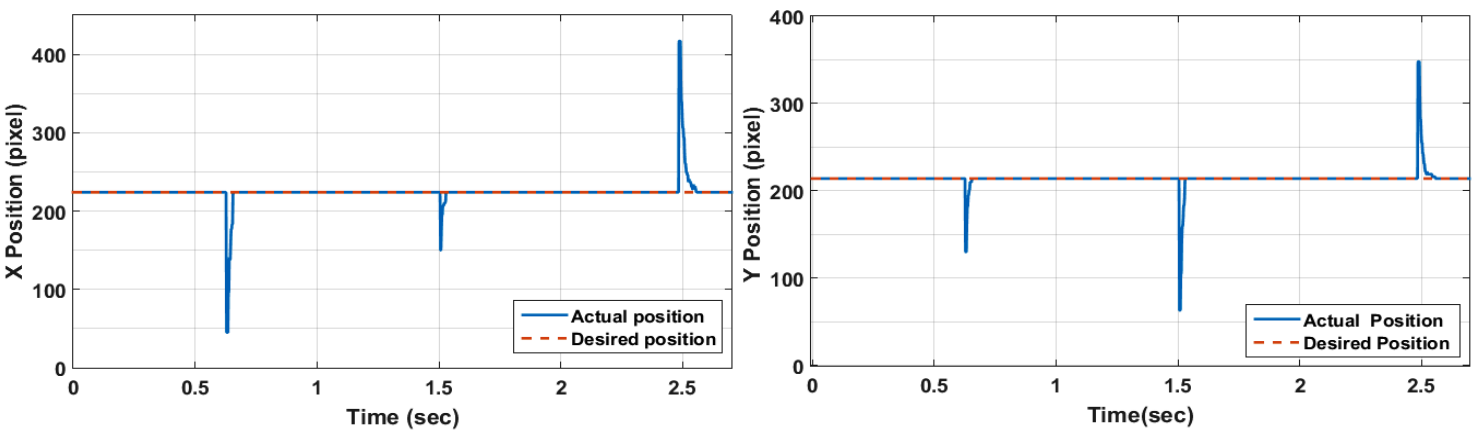

Figure 9. Disturbance Rejection from the Output Response of the System

\section{CONCLUSION}

This paper described the development of remotely controlled LP for teleconsultation with vison feedback. The most important part of this system is the performance of the controller. Good control performance was achieved by tuning the PID controller using Ziegler-Nichols method. The tuned controllers not only resulted in very fast response without no overshoot, but it is also robust against changes in the sampling time and external disturbance.

\section{ACKNOWLEDGEMENTS}

The authors would like to acknowledge MOSTI and UKM for Science Fund 01-01-02-SF0882 and GUP-2013-035. In addition, we thank Dr. Edgar Scavino and Mr. Mohd Hanif Md Saad for their help in the initial settings of the experiment.

\section{REFERENCES}

[1] Karim RA, Zakaria NF, Zulkifley MA, Mustafa MM, Sagap I, Latar NH. Telepointer technology in telemedicine: a review. Biomedical engineering online. 2013 Mar 9; 12(1): 1.

[2] Mann S. Telepointer: Hands-free completely self-contained wearable visual augmented reality without headwear and without any infrastructural reliance. InWearable Computers, The Fourth International Symposium on 2000 Oct 16 (pp. 177-178). IEEE.

[3] Chen Y, Ma YJ, Yun WX. Application of Improved Genetic Algorithm in PID Controller Parameters Optimization. TELKOMNIKA Indonesian Journal of Electrical Engineering. 2013 Mar 3; 11(3): 1524-30.

[4] Cahyadi AI, Hooi NK, Persada A. Design and Experiments of Low Cost Teleoperation System. IAES International Journal of Robotics and Automation. 2012 Mar 1; 1(1): 1. 
[5] Hutchinson S, Hager GD, Corke PI. A tutorial on visual servo control. IEEE transactions on robotics and automation. 1996 Oct; 12(5): 651-70.

[6] Chaumette F, Hutchinson S. Visual servo control. I. Basic approaches. IEEE Robotics \& Automation Magazine. 2006 Dec; 13(4): 82-90.

[7] Derhgawen A.Webcam Based Laser Tracking for Human-Computer Interaction.Apr. 2008. [Online].Available: https://channel9.msdn.com/coding4fun/articles/Webcam-Based-Laser-Tracking-for-Human-Computer-Interaction

[8] Lcady.PID process control, a "Cruise Control" example. CodeProject.May.2009[Online].Available: http://www.codeproject.com/Articles/36459/PID-process-control-a-Cruise-Control-example

[9] Astrom K.J , Hagglund T. PID Controllers, Theory, Design and Tuning. (2nd Edition), Instrument Society of America (1995)

[10] Ziegler JG, Nichols NB. Optimum settings for automatic controllers. trans. ASME. 1942 Nov; 64(11): 759 - 768. 